\begin{tabular}{|c|c|c|c|}
\hline Declination ... & & & $\mathrm{x}^{\circ} 54^{\prime} .72 \mathrm{~W}$ \\
\hline Dip ... $\quad \ldots$ & & $\ldots$ & $\ldots 46^{\circ} \quad 15^{\prime}$ \\
\hline Total Force... & $\ldots$ & $\cdots$ & $\ldots$ I0.04850 \\
\hline
\end{tabular}

The value of the declination is very reliable, as it depends on observations taken every half hour from $6 \mathrm{~A}$. M. to $6 \mathrm{P}$.M. on four days each month in 1874, and on eight days a month in 1875 . The dip results from six complete observations, and the horizontal component of the intensity was determined twice a month in 1874 , and every week in 1875 .

Previous dip observations at Shang-Hai, by Sir E. Home in 1843 , and by Capt. Shadwell in $185^{\circ}$, give $-2^{\prime} \cdot 2$ and $-3^{\prime} \cdot 4$ as the secular variation for $185 \mathrm{I}$ and 1862 , the latter differing but slightly from the present variation in England.

Comparing the monthly means of the horizontal force for the winter and summer of 1874-75, we find an excess of 0.00074 in favour of the winter, when the sun is nearest the earth. The extreme variation is only 0.00577 , and both maximum and minimum occur in the summer months.

From a limited number of night observations it appears that the range of the declination needle is much more confined, whilst the sun is below the horizon than during the day hours. The diurnal variation is regular throughout the year, but the daily changes in winter are less simple than those of summer. The following are the mean results for the serarate seasons :-

$$
\text { Mean. Min. at Max. at }
$$

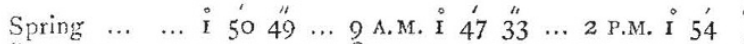

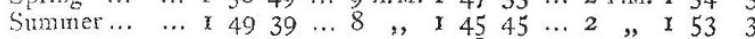

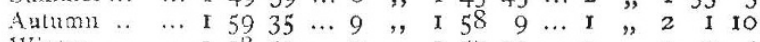

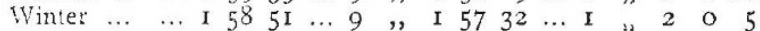

The time of the principal minimum is more constant than that of the maximum, the latter being anticipated by one hour in wioter

A sudden change from $x^{\circ} 50^{\prime} 13^{\prime \prime}$ on Sept. 21 to $1^{\circ} 56^{\prime} 5 I^{\prime \prime}$ on Sept. 26, 1874 , seems to require further confirmation (which it did not receive in 1875 ) before it can be considered as more than accidentally connected with the passage of the sun through the autumnal equinox.

The monthly mean value of the declination is greatest in November and least in June, and the absolute maximum and minimum were :-

and

$$
2^{\circ} 3^{\prime} 49^{\prime \prime} \text { at I ih. I } 5 \text { m. A.M. on November } 8 \text {, }
$$

$\mathrm{I}^{\circ} 4 \mathrm{I}^{\prime} 58^{\prime \prime}$ at 9 A.M. on June 29.

giving a yearly range of only $2 \mathrm{I}^{\prime} 5 \mathrm{I}^{\prime \prime}$, whilst the secular variation iamolmis to $+5^{\prime} \cdot 85$. The value on Nov. 8 was also evidently irceased by some irregular disturbance.

The comparison of the yearly means for the different hours with the hourly means for each season, shows that the sun's position with regatd to the equator has a decided effect on the magnetic declination, as increase and diminution in summer invariably correspond with diminution and increase in winter.

In discussing the hourly velocity of the needle, it is found that the acceleration is greatest between IO and II A.M., when the mignet is near its mean position, and that the A.M. max'mum velocity is an hour earlier, and the P.M. maximum an hour later in summer than in winter, the greatest velocity being about. $1^{\prime \prime} \cdot 5$ par minute.

The mean amplitude of the daily excursions of the declination magnet is $7^{\prime} \cdot 88$ in summer against $3^{\prime} \cdot 68$ in winter, June giving the raximum mean amplitude of $9^{\prime} \cdot 06$, and December the minimum of $2^{\prime} \cdot 95$. The value of $\mathbf{r}^{\prime} \cdot 92$ in February appears to be exceptional. The greatest extent of a daily oscillation in the cnurse of the twelve months was $I I^{\prime} \circ 5$ on June $I$, and the least $1^{\prime} \cdot \mathrm{r} 3$ on Feb. 20 , giving a maximum yearly variation of $9^{\prime} \cdot 92$.

The changes of the magnetic elements appear to be remarkably small throughout, and very free from irregular disturbances. The cure with which the observations are taken, and the efficient way in which they are discussed, are an earnest of the plentiful harvest we have every reason to expect from this land once so famous, but hitherto so neglected by modern science.

Stonyhurst Observatory, April I3

S. J. Perry

\section{THE CHALLENGER EXPEDITION}

$\mathrm{WE}$ have great pleasure in availing ourselves of the permission to publish the following correspondence which has passed through our hands, and in congratulating the staff of the Challenger, on having deserved so weighty a testimonial of success. It is an additional assurance that their three years' labour has not been in vain, that so many distinguished men of science have been impelled to speak of it in such terms, as well as a guarantee to the British Government that they did a wise thing in equipping the expedition; we hope it will be an encouragement to the latter to continue to deserve such golden opinions. To the Editor of "Nature"

Vienna, June 12,1876

SIR, - After having followed the reports of the naturalists of H.M.S. Challenger with the utmost interest, we beg leave to ask you kindly to transmit this simple but sincere expression of a hearty welcome and of thankful admiration to these distinguished gentlemen, as well as to the officers and the crew of this gallant ship, which has been called to render such prominent services to science. Yours most respectfully,

EDw. Suess, M. P. Prof. University, Vienna,

C. Claus,

G. TSCHERMAK,

F. STEINDACHNER, Director of the Imper. Zoolog. Museum,

Dr. Fr. Brauer, Custos of the Imper. Zoolog. Museum,

E. v. MARENZELLER,

Prof. Dr. J. HanN,

F. KARRER,

TH. Fuchs, Custos am k.k. Hof. Min. Cab.,

Palzeln, Custos am k.k. Zoolog. Cabinete.

To this the following reply has been made by Sir C. Thomson :-

To the Editor of "Nature"

20, Palmerston Place, Edinburgh, June 23, 1876

MY dear Sir, - I received your note and enclosure last evening. Will you allow me through you to express on my own part and on that of my colleagues Civilian and Naval on board the Chal. lenger, our deep gratification at the kind way in which the leaders of Natural Science in Vienna have expressed their approval of our efforts to extend the limits of knowledge in Phy sical Geography?

We hope that the Empire, which by the most instructive voyage of the Novara immediately preceded us in a similar line of research, may be among the first to aid in filling up the rich details of the new zoological region of which we have been able hitherto to supply only an outline.

I am, my dear Sir, yours very faithfully, C. WYVILLE THOMSON,

Director of the Civilian Scientific Staff of the Challenger Expedition.

ABSTRACT REPORT TO "NATURE" ON EXPERIMENTATION ON ANIMALS FOR THE ADVANCE OF PRACTICAL MEDICINE'

III.

\section{Experimental Researches on Ancesthesia Local and} General.

$T$ HE revival of methods for rendering surgical operations on men and animals perfectly painless, while it has been one of the greatest of the advances of modern medical art, has not been without its alloy. The present generation can scarcely appreciate what were the scenes of the operating theatre before the introduction of anæsthesia. The present generation that is not medical cannot appreciate now what is the scene at an operation when the agent employed to prevent pain proves an agent of death. One surgeon I know has been present at six of these fatal catastrophes under and from anæsthetics. Such an experience shakes the strongest heart. Here is a human being talking cheerfully and resigning himself with full confidence to his medical friends. The operation to be performed may be the act of seconds ${ }^{1}$ Continued trom p. ${ }^{5} 2$. 